\title{
A SOCIOLOGIA E
}

AS QUESTÕES INTERPOSTAS AO DESENVOLVIMENTO HUMANO 3

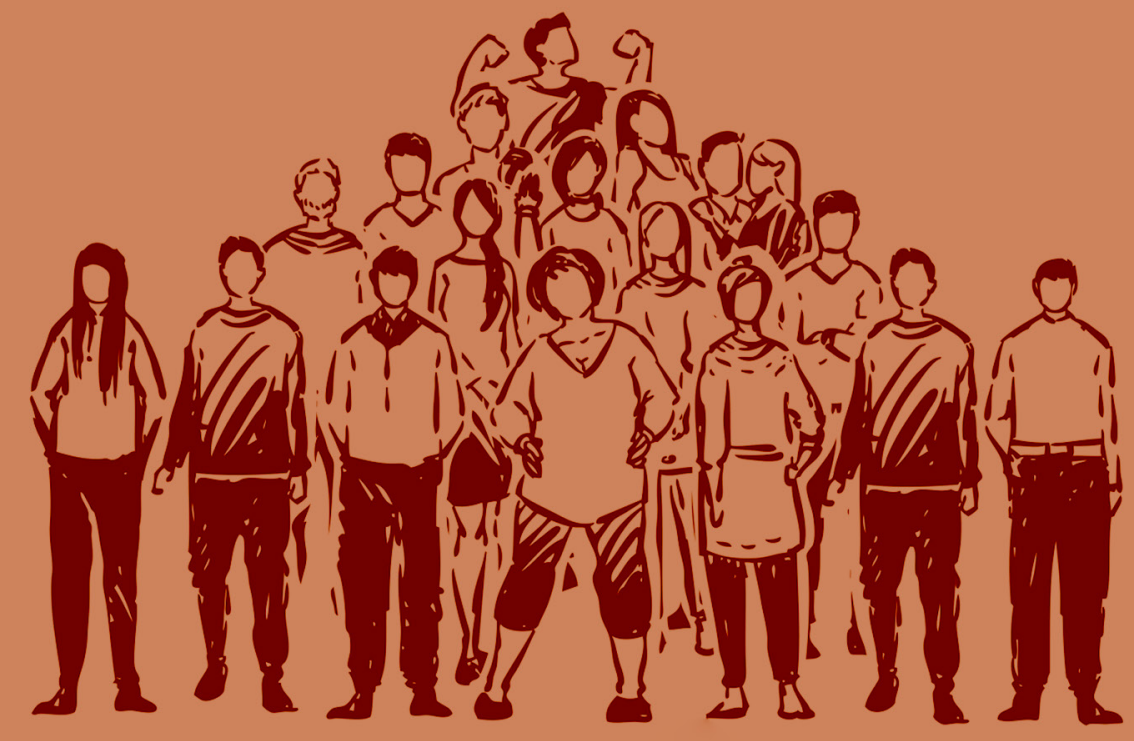

\section{ALEXSANDRO TEIXEIRA RIBEIRO}

(ORGANIZADOR)

Antena 


\section{A SOCIOLOGIA E}

AS QUESTÕES INTERPOSTAS AO DESENVOLVIMENTO HUMANO 3

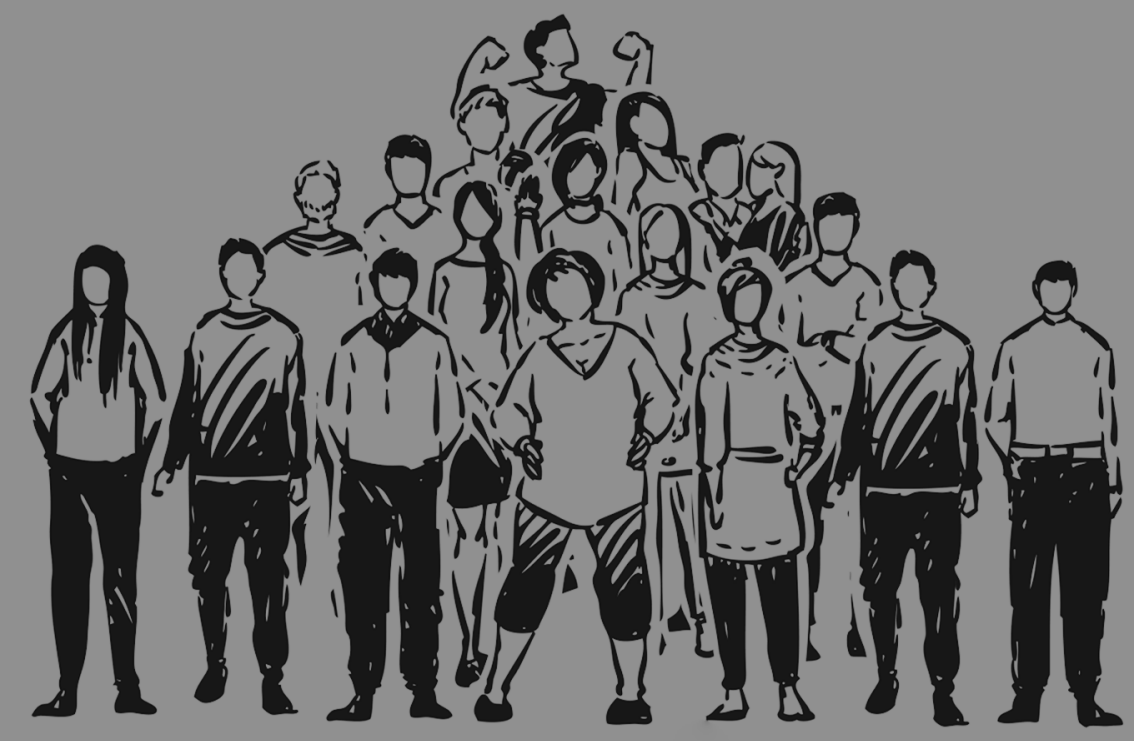

\section{ALEXSANDRO TEIXEIRA RIBEIRO}

(ORGANIZADOR)

Antena 
Editora Chefe

Prof $^{a}$ Dr $^{\mathrm{a}}$ Antonella Carvalho de Oliveira

Assistentes Editoriais

Natalia Oliveira

Bruno Oliveira

Flávia Roberta Barão

Bibliotecária

Janaina Ramos

Projeto Gráfico e Diagramação

Natália Sandrini de Azevedo

Camila Alves de Cremo

Luiza Alves Batista

Maria Alice Pinheiro

Imagens da Capa

Shutterstock

Edição de Arte

Luiza Alves Batista

Revisão

Os Autores
2020 by Atena Editora

Copyright (c) Atena Editora

Copyright do Texto (c) 2020 Os autores

Copyright da Edição (c) 2020 Atena Editora

Direitos para esta edição cedidos à Atena

Editora pelos autores.

Todo o conteúdo deste livro está licenciado sob uma Licença de

\section{(c) $(1) \Theta \Theta$}

Atribuição Creative Commons. Atribuição-Não-ComercialNãoDerivativos 4.0 Internacional (CC BY-NC-ND 4.0).

O conteúdo dos artigos e seus dados em sua forma, correção e confiabilidade são de responsabilidade exclusiva dos autores, inclusive não representam necessariamente a posição oficial da Atena Editora. Permitido o download da obra e o compartilhamento desde que sejam atribuídos créditos aos autores, mas sem a possibilidade de alterá-la de nenhuma forma ou utilizá-la para fins comerciais.

A Atena Editora não se responsabiliza por eventuais mudanças ocorridas nos endereços convencionais ou eletrônicos citados nesta obra.

Todos os manuscritos foram previamente submetidos à avaliação cega pelos pares, membros do Conselho Editorial desta Editora, tendo sido aprovados para a publicação.

\section{Conselho Editorial}

\section{Ciências Humanas e Sociais Aplicadas}

Prof. Dr. Alexandre Jose Schumacher - Instituto Federal de Educação, Ciência e Tecnologia do Paraná

Prof. Dr. Américo Junior Nunes da Silva - Universidade do Estado da Bahia

Prof. Dr. Antonio Carlos Frasson - Universidade Tecnológica Federal do Paraná

Prof. Dr. Antonio Gasparetto Júnior - Instituto Federal do Sudeste de Minas Gerais

Prof. Dr. Antonio Isidro-Filho - Universidade de Brasília

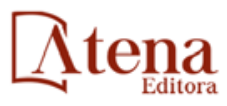


Prof. Dr. Carlos Antonio de Souza Moraes - Universidade Federal Fluminense

Prof $^{a}$ Dr $^{\text {a }}$ Cristina Gaio - Universidade de Lisboa

Prof. Dr. Daniel Richard Sant'Ana - Universidade de Brasília

Prof. Dr. Deyvison de Lima Oliveira - Universidade Federal de Rondônia

Prof $^{\mathrm{a}}$ Dr $^{\mathrm{a}}$ Dilma Antunes Silva - Universidade Federal de São Paulo

Prof. Dr. Edvaldo Antunes de Farias - Universidade Estácio de Sá

Prof. Dr. Elson Ferreira Costa - Universidade do Estado do Pará

Prof. Dr. Eloi Martins Senhora - Universidade Federal de Roraima

Prof. Dr. Gustavo Henrique Cepolini Ferreira - Universidade Estadual de Montes Claros

Prof $^{a} \mathrm{Dr}^{\mathrm{a}}$ Ivone Goulart Lopes - Istituto Internazionele delle Figlie de Maria Ausiliatrice

Prof. Dr. Jadson Correia de Oliveira - Universidade Católica do Salvador

Prof. Dr. Julio Candido de Meirelles Junior - Universidade Federal Fluminense

Prof $^{\mathrm{a}} \mathrm{Dr}^{\mathrm{a}}$ Lina Maria Gonçalves - Universidade Federal do Tocantins

Prof. Dr. Luis Ricardo Fernandes da Costa - Universidade Estadual de Montes Claros

Prof $^{a}$ Dr $^{a}$ Natiéli Piovesan - Instituto Federal do Rio Grande do Norte

Prof. Dr. Marcelo Pereira da Silva - Pontifícia Universidade Católica de Campinas

Prof $^{a}$ Dr $^{a}$ Maria Luzia da Silva Santana - Universidade Federal de Mato Grosso do Sul

Prof ${ }^{a}$ Dr $^{a}$ Paola Andressa Scortegagna - Universidade Estadual de Ponta Grossa

Prof $^{a}$ Dr $^{a}$ Rita de Cássia da Silva Oliveira - Universidade Estadual de Ponta Grossa

Prof. Dr. Rui Maia Diamantino - Universidade Salvador

Prof. Dr. Urandi João Rodrigues Junior - Universidade Federal do Oeste do Pará

Prof $^{a}$ Dr $^{a}$ Vanessa Bordin Viera - Universidade Federal de Campina Grande

Prof. Dr. William Cleber Domingues Silva - Universidade Federal Rural do Rio de Janeiro

Prof. Dr. Willian Douglas Guilherme - Universidade Federal do Tocantins

\section{Ciências Agrárias e Multidisciplinar}

Prof. Dr. Alexandre Igor Azevedo Pereira - Instituto Federal Goiano

Prof $^{a}$ Dr $^{a}$ Carla Cristina Bauermann Brasil - Universidade Federal de Santa Maria

Prof. Dr. Antonio Pasqualetto - Pontifícia Universidade Católica de Goiás

Prof. Dr. Cleberton Correia Santos - Universidade Federal da Grande Dourados

Prof $^{a}$ Dr $^{\mathrm{a}}$ Daiane Garabeli Trojan - Universidade Norte do Paraná

Prof ${ }^{a}$ Dr $^{a}$ Diocléa Almeida Seabra Silva - Universidade Federal Rural da Amazônia

Prof. Dr. Écio Souza Diniz - Universidade Federal de Viçosa

Prof. Dr. Fábio Steiner - Universidade Estadual de Mato Grosso do Sul

Prof. Dr. Fágner Cavalcante Patrocínio dos Santos - Universidade Federal do Ceará

Prof ${ }^{a}$ Dr $^{a}$ Girlene Santos de Souza - Universidade Federal do Recôncavo da Bahia

Prof. Dr. Jael Soares Batista - Universidade Federal Rural do Semi-Árido

Prof. Dr. Júlio César Ribeiro - Universidade Federal Rural do Rio de Janeiro

Prof $^{a}$ Dr $^{a}$ Lina Raquel Santos Araújo - Universidade Estadual do Ceará

Prof. Dr. Pedro Manuel Villa - Universidade Federal de Viçosa

Prof $^{\mathrm{a}}$ Dr $^{\mathrm{a}}$ Raissa Rachel Salustriano da Silva Matos - Universidade Federal do Maranhão

Prof. Dr. Ronilson Freitas de Souza - Universidade do Estado do Pará

Prof $^{a}$ Dr $^{a}$ Talita de Santos Matos - Universidade Federal Rural do Rio de Janeiro

Prof. Dr. Tiago da Silva Teófilo - Universidade Federal Rural do Semi-Árido

Prof. Dr. Valdemar Antonio Paffaro Junior - Universidade Federal de Alfenas

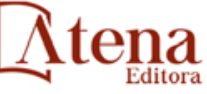

Ano 2020 


\section{Ciências Biológicas e da Saúde}

Prof. Dr. André Ribeiro da Silva - Universidade de Brasília

Prof $^{a}$ Dr $^{a}$ Anelise Levay Murari - Universidade Federal de Pelotas

Prof. Dr. Benedito Rodrigues da Silva Neto - Universidade Federal de Goiás

Prof $^{\mathrm{a}} \mathrm{Dr}^{\mathrm{a}}$ Débora Luana Ribeiro Pessoa - Universidade Federal do Maranhão

Prof. Dr. Douglas Siqueira de Almeida Chaves -Universidade Federal Rural do Rio de Janeiro

Prof. Dr. Edson da Silva - Universidade Federal dos Vales do Jequitinhonha e Mucuri

Prof $^{a}$ Dr $^{a}$ Eleuza Rodrigues Machado - Faculdade Anhanguera de Brasília

Prof $^{a}$ Dr $^{a}$ Elane Schwinden Prudêncio - Universidade Federal de Santa Catarina

Prof $^{\mathrm{a}} \mathrm{Dr}^{\mathrm{a}}$ Eysler Gonçalves Maia Brasil - Universidade da Integração Internacional da Lusofonia Afro-Brasileira

Prof. Dr. Ferlando Lima Santos - Universidade Federal do Recôncavo da Bahia

Prof $^{a}$ Dr $^{a}$ Gabriela Vieira do Amaral - Universidade de Vassouras

Prof. Dr. Gianfábio Pimentel Franco - Universidade Federal de Santa Maria

Prof. Dr. Helio Franklin Rodrigues de Almeida - Universidade Federal de Rondônia

Prof $^{a}$ Dr $^{a}$ lara Lúcia Tescarollo - Universidade São Francisco

Prof. Dr. Igor Luiz Vieira de Lima Santos - Universidade Federal de Campina Grande

Prof. Dr. Jefferson Thiago Souza - Universidade Estadual do Ceará

Prof. Dr. Jesus Rodrigues Lemos - Universidade Federal do Piauí

Prof. Dr. Jônatas de França Barros - Universidade Federal do Rio Grande do Norte

Prof. Dr. José Max Barbosa de Oliveira Junior - Universidade Federal do Oeste do Pará

Prof. Dr. Luís Paulo Souza e Souza - Universidade Federal do Amazonas

Prof $^{a}$ Dr $^{a}$ Magnólia de Araújo Campos - Universidade Federal de Campina Grande

Prof. Dr. Marcus Fernando da Silva Praxedes - Universidade Federal do Recôncavo da Bahia

Prof ${ }^{a} \operatorname{Dr}^{a}$ Maria Tatiane Gonçalves Sá - Universidade do Estado do Pará

Prof $^{a}$ Dr $^{a}$ Mylena Andréa Oliveira Torres - Universidade Ceuma

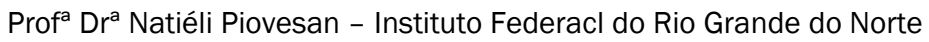

Prof. Dr. Paulo Inada - Universidade Estadual de Maringá

Prof. Dr. Rafael Henrique Silva - Hospital Universitário da Universidade Federal da Grande Dourados

Prof ${ }^{a}$ Dr $^{a}$ Regiane Luz Carvalho - Centro Universitário das Faculdades Associadas de Ensino

Prof $^{a}$ Dr $^{a}$ Renata Mendes de Freitas - Universidade Federal de Juiz de Fora

Prof $^{a}$ Dr $^{\text {a }}$ Vanessa Lima Gonçalves - Universidade Estadual de Ponta Grossa

Prof $^{a}$ Dr $^{\mathrm{a}}$ Vanessa Bordin Viera - Universidade Federal de Campina Grande

\section{Ciências Exatas e da Terra e Engenharias}

Prof. Dr. Adélio Alcino Sampaio Castro Machado - Universidade do Porto

Prof. Dr. Carlos Eduardo Sanches de Andrade - Universidade Federal de Goiás

Prof ${ }^{a}$ Dr $^{a}$ Carmen Lúcia Voigt - Universidade Norte do Paraná

Prof. Dr. Douglas Gonçalves da Silva - Universidade Estadual do Sudoeste da Bahia

Prof. Dr. Eloi Rufato Junior - Universidade Tecnológica Federal do Paraná

Prof $^{a}$ Dr $^{a}$ Érica de Melo Azevedo - Instituto Federal do Rio de Janeiro

Prof. Dr. Fabrício Menezes Ramos - Instituto Federal do Pará

Prof $^{a}$ Dra. Jéssica Verger Nardeli - Universidade Estadual Paulista Júlio de Mesquita Filho

Prof. Dr. Juliano Carlo Rufino de Freitas - Universidade Federal de Campina Grande

Prof $^{\mathrm{a}} \mathrm{Dr}^{\mathrm{a}}$ Luciana do Nascimento Mendes - Instituto Federal de Educação, Ciência e Tecnologia

do Rio Grande do Norte

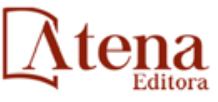

Ano 2020 
Prof. Dr. Marcelo Marques - Universidade Estadual de Maringá

Prof $^{a} D^{a}{ }^{a}$ Neiva Maria de Almeida - Universidade Federal da Paraíba

Prof $^{a}$ Dra $^{a}$ Natiéli Piovesan - Instituto Federal do Rio Grande do Norte

Prof ${ }^{a}$ Dr $^{a}$ Priscila Tessmer Scaglioni - Universidade Federal de Pelotas

Prof. Dr. Takeshy Tachizawa - Faculdade de Campo Limpo Paulista

\section{Linguística, Letras e Artes}

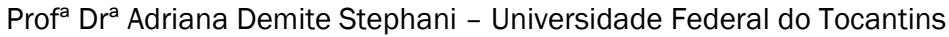

Prof $^{\mathrm{a}} \mathrm{Dr}^{\mathrm{a}}$ Angeli Rose do Nascimento - Universidade Federal do Estado do Rio de Janeiro

Prof $^{a}$ Dr $^{a}$ Carolina Fernandes da Silva Mandaji - Universidade Tecnológica Federal do Paraná

Prof $^{a}$ Dr $^{a}$ Denise Rocha - Universidade Federal do Ceará

Prof. Dr. Fabiano Tadeu Grazioli - Universidade Regional Integrada do Alto Uruguai e das Missões

Prof. Dr. Gilmei Fleck - Universidade Estadual do Oeste do Paraná

Prof $^{a}$ Dr $^{a}$ Keyla Christina Almeida Portela - Instituto Federal de Educação, Ciência e Tecnologia do Paraná

Prof $^{a}$ Dr $^{a}$ Miranilde Oliveira Neves - Instituto de Educação, Ciência e Tecnologia do Pará

Prof $^{a}$ Dr $^{a}$ Sandra Regina Gardacho Pietrobon - Universidade Estadual do Centro-Oeste

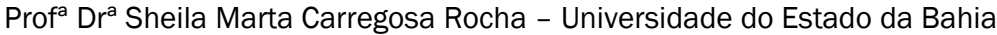

\section{Conselho Técnico Científico}

Prof. Me. Abrãao Carvalho Nogueira - Universidade Federal do Espírito Santo

Prof. Me. Adalberto Zorzo - Centro Estadual de Educação Tecnológica Paula Souza

Prof. Me. Adalto Moreira Braz - Universidade Federal de Goiás

Prof. Dr. Adaylson Wagner Sousa de Vasconcelos - Ordem dos Advogados do Brasil/Seccional Paraíba

Prof. Dr. Adilson Tadeu Basquerote Silva - Universidade para o Desenvolvimento do Alto Vale do Itajaí

Prof. Me. Alexsandro Teixeira Ribeiro - Centro Universitário Internacional

Prof. Me. André Flávio Gonçalves Silva - Universidade Federal do Maranhão

Prof ${ }^{a}$ Ma. Andréa Cristina Marques de Araújo - Universidade Fernando Pessoa

Prof $^{a}$ Dr $^{\text {a }}$ Andreza Lopes - Instituto de Pesquisa e Desenvolvimento Acadêmico

Prof $^{\text {a }}$ Dr $^{\text {a }}$ Andrezza Miguel da Silva - Faculdade da Amazônia

Prof ${ }^{a}$ Ma. Anelisa Mota Gregoleti - Universidade Estadual de Maringá

Profa Ma. Anne Karynne da Silva Barbosa - Universidade Federal do Maranhão

Prof. Dr. Antonio Hot Pereira de Faria - Polícia Militar de Minas Gerais

Prof. Me. Armando Dias Duarte - Universidade Federal de Pernambuco

Prof ${ }^{a}$ Ma. Bianca Camargo Martins - UniCesumar

Prof $^{a}$ Ma. Carolina Shimomura Nanya - Universidade Federal de São Carlos

Prof. Me. Carlos Antônio dos Santos - Universidade Federal Rural do Rio de Janeiro

Prof. Ma. Cláudia de Araújo Marques - Faculdade de Música do Espírito Santo

Prof ${ }^{\mathrm{a}}$ Dr $^{\mathrm{a}}$ Cláudia Taís Siqueira Cagliari - Centro Universitário Dinâmica das Cataratas

Prof. Me. Clécio Danilo Dias da Silva - Universidade Federal do Rio Grande do Norte

Prof. Me. Daniel da Silva Miranda - Universidade Federal do Pará

Prof $^{a}$ Ma. Daniela da Silva Rodrigues - Universidade de Brasília

Prof ${ }^{a}$ Ma. Daniela Remião de Macedo - Universidade de Lisboa

Prof $^{a}$ Ma. Dayane de Melo Barros - Universidade Federal de Pernambuco

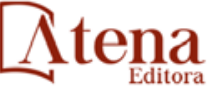


Prof. Me. Douglas Santos Mezacas - Universidade Estadual de Goiás

Prof. Me. Edevaldo de Castro Monteiro - Embrapa Agrobiologia

Prof. Me. Eduardo Gomes de Oliveira - Faculdades Unificadas Doctum de Cataguases

Prof. Me. Eduardo Henrique Ferreira - Faculdade Pitágoras de Londrina

Prof. Dr. Edwaldo Costa - Marinha do Brasil

Prof. Me. Eliel Constantino da Silva - Universidade Estadual Paulista Júlio de Mesquita

Prof. Me. Ernane Rosa Martins - Instituto Federal de Educação, Ciência e Tecnologia de Goiás

Prof. Me. Euvaldo de Sousa Costa Junior - Prefeitura Municipal de São João do Piauí

Prof $^{a}$ Ma. Fabiana Coelho Couto Rocha Corrêa - Centro Universitário Estácio Juiz de Fora

Prof. Dr. Fabiano Lemos Pereira - Prefeitura Municipal de Macaé

Prof. Me. Felipe da Costa Negrão - Universidade Federal do Amazonas

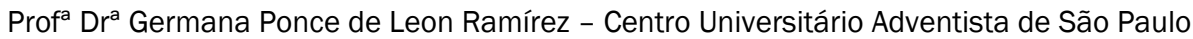

Prof. Me. Gevair Campos - Instituto Mineiro de Agropecuária

Prof. Me. Givanildo de Oliveira Santos - Secretaria da Educação de Goiás

Prof. Dr. Guilherme Renato Gomes - Universidade Norte do ParanáProf. Me. Gustavo Krahl Universidade do Oeste de Santa Catarina

Prof. Me. Helton Rangel Coutinho Junior - Tribunal de Justiça do Estado do Rio de Janeiro

Prof $^{a}$ Ma. Isabelle Cerqueira Sousa - Universidade de Fortaleza

Prof ${ }^{a}$ Ma. Jaqueline Oliveira Rezende - Universidade Federal de Uberlândia

Prof. Me. Javier Antonio Albornoz - University of Miami and Miami Dade College

Prof. Me. Jhonatan da Silva Lima - Universidade Federal do Pará

Prof. Dr. José Carlos da Silva Mendes - Instituto de Psicologia Cognitiva, Desenvolvimento Humano e Social

Prof. Me. Jose Elyton Batista dos Santos - Universidade Federal de Sergipe

Prof. Me. José Luiz Leonardo de Araujo Pimenta - Instituto Nacional de Investigación Agropecuaria Uruguay

Prof. Me. José Messias Ribeiro Júnior - Instituto Federal de Educação Tecnológica de Pernambuco

Prof $^{a}{ }^{\mathrm{a}}{ }^{\mathrm{a}}$ Juliana Santana de Curcio - Universidade Federal de Goiás

Prof $^{a}$ Ma. Juliana Thaisa Rodrigues Pacheco - Universidade Estadual de Ponta Grossa

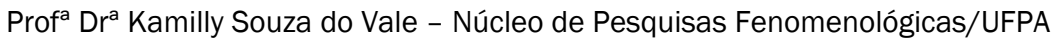

Prof. Dr. Kárpio Márcio de Siqueira - Universidade do Estado da Bahia

Prof $^{a}$ Dr $^{a}$ Karina de Araújo Dias - Prefeitura Municipal de Florianópolis

Prof. Dr. Lázaro Castro Silva Nascimento - Laboratório de Fenomenologia \& Subjetividade/UFPR

Prof. Me. Leonardo Tullio - Universidade Estadual de Ponta Grossa

Prof $^{\mathrm{a}} \mathrm{Ma}$. Lilian Coelho de Freitas - Instituto Federal do Pará

Prof ${ }^{a}$ Ma. Liliani Aparecida Sereno Fontes de Medeiros - Consórcio CEDERJ

Prof ${ }^{a}$ Dra $^{a}$ Lívia do Carmo Silva - Universidade Federal de Goiás

Prof. Dr. Lucio Marques Vieira Souza - Secretaria de Estado da Educação, do Esporte e da Cultura de Sergipe

Prof. Me. Luis Henrique Almeida Castro - Universidade Federal da Grande Dourados

Prof. Dr. Luan Vinicius Bernardelli - Universidade Estadual do Paraná

Prof. Dr. Michel da Costa - Universidade Metropolitana de Santos

Prof. Dr. Marcelo Máximo Purificação - Fundação Integrada Municipal de Ensino Superior

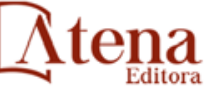


Prof. Me. Marcos Aurelio Alves e Silva - Instituto Federal de Educação, Ciência e Tecnologia de São Paulo

Prof ${ }^{a}$ Ma. Maria Elanny Damasceno Silva - Universidade Federal do Ceará

Prof ${ }^{a}$ Ma. Marileila Marques Toledo - Universidade Federal dos Vales do Jequitinhonha e Mucuri

Prof. Me. Ricardo Sérgio da Silva - Universidade Federal de Pernambuco

Prof $^{a}$ Ma. Renata Luciane Polsaque Young Blood - UniSecal

Prof. Me. Robson Lucas Soares da Silva - Universidade Federal da Paraíba

Prof. Me. Sebastião André Barbosa Junior - Universidade Federal Rural de Pernambuco

Prof $^{a}$ Ma. Silene Ribeiro Miranda Barbosa - Consultoria Brasileira de Ensino, Pesquisa e Extensão

Prof $^{a}$ Ma. Solange Aparecida de Souza Monteiro - Instituto Federal de São Paulo

Prof. Me. Tallys Newton Fernandes de Matos - Faculdade Regional Jaguaribana

Prof $^{a}$ Ma. Thatianny Jasmine Castro Martins de Carvalho - Universidade Federal do Piauí

Prof. Me. Tiago Silvio Dedoné - Colégio ECEL Positivo

Prof. Dr. Welleson Feitosa Gazel - Universidade Paulista 
Editora Chefe: Prof $^{\mathrm{a}} \mathrm{Dr}^{\mathrm{a}}$ Antonella Carvalho de Oliveira

Bibliotecária: Janaina Ramos

Diagramação: Camila Alves de Cremo

Correção: Vanessa Mottin de Oliveira Batista

Edição de Arte: Luiza Alves Batista

Revisão: Os Autores

Organizador: Alexsandro Teixeira Ribeiro

Dados Internacionais de Catalogação na Publicação (CIP)

S678 A sociologia e as questões interpostas ao desenvolvimento humano 3 / Organizador Alexsandro Teixeira Ribeiro. Ponta Grossa - PR: Atena, 2020.

Formato: PDF

Requisitos de sistema: Adobe Acrobat Reader Modo de acesso: World Wide Web

Inclui bibliografia

ISBN 978-65-5706-538-9

DOI 10.22533/at.ed.389202810

1. Sociologia. 2. Desenvolvimento Humano. I. Ribeiro, Alexsandro Teixeira (Organizador). II. Título.

CDD 301

Elaborado por Bibliotecária Janaina Ramos - CRB-8/9166

Atena Editora

Ponta Grossa - Paraná - Brasil

Telefone: +55 (42) 3323-5493

www.atenaeditora.com.br contato@atenaeditora.com.br 


\section{APRESENTAÇÃO}

Pensar e sociedade, o indivíduo, a intersubjetividade e as relações sociais são preocupações constantes nos artigos e capítulos que integram a obra "A Sociologia e as Questões Interpostas ao Desenvolvimento Humano 3". O livro reúne uma série de contribuições da pesquisa social que buscam dar os contornos sobre a vida em sociedade, sobre as identidades e comunidades sociais.

A variedade de olhares que surgem nos capítulos dá conta de uma abordagem ampla sobre diversos temas atuais e urgentes. Sobretudo de questões relacionadas aos processos identitários, à etnicidade, dentre outros. Aqui, destacamse os trabalhos que abordam as redes de interdependências estabelecidas a partir dos jogos indígenas, a tradição e a sobrevivência de comunidades pesqueiras portuguesas, entre comunidades geracionais, grupos de trabalho e identidades profissionais.

As vulnerabilidades social e laboral também são evidenciadas e debatidas à luz das correntes sociológicas nos trabalhos aqui destacados. Dentre eles podemos ressaltas pesquisas sobre políticas públicas para dependentes de novas drogas psicoativas, a precarização do trabalho e as condições sanitárias no mercado sexual durante a pandemia, as redes de apoio e grupos de identidade vinculados às pessoas em situação de rua, e as condições de representatividades da comunidade carcerária.

O rigor metodológico e as contribuições de múltiplas observações do campo social faz da coleção "A Sociologia e as Questões Interpostas ao Desenvolvimento Humano 3" uma obra que contribui para o campo científico nacional. 


\section{SUMÁRIO}

CAPÍTULO 1

GEORG SIMMEL E A EDUCAÇÃO COMO TRAGÉDIA

Elson dos Santos Gomes Junior

Rafael Ferreira Pureza de Oliveira

Marcos Felipe Medeiros de Souza

DOI 10.22533/at.ed.3892028101

CAPÍTULO 2

ENTRE TRADIÇÃO E SOBREVIVÊNCIA DO TRABALHO DO MAR: DILEMAS GERACIONAIS DAS COMUNIDADES PISCATÓRIAS PORTUGUESAS

Licínio Manuel Vicente Tomás

DOI 10.22533/at.ed.3892028102

CAPÍTULO 3 28

EDUCAÇÃO INFORMAL E EXPERIÊNCIA MIGRATÓRIA: INVESTIGAÇÃO SOBRE SENIORES RESIDENTES EM VIANA DO CASTELO

Manuela Benvinda Vieira Gomes Cachadinha

DOI 10.22533/at.ed.3892028103

CAPÍTULO 4 41

UMA ANÁLISE SOBRE AS POLÍTICAS PÚBLICAS E OS MERCADOS DAS NOVAS SUBSTÂNCIAS PSICOATIVAS (NSP)

Susana Henriques

Maria das Dores Guerreiro

Joana Paula Silva

DOI 10.22533/at.ed.3892028104

CAPÍTULO 5 55

SABERES TRADICIONAIS: UMA PESQUISA PARTICIPANTE REALIZADA COM O MOVIMENTO DAS APRENDIZES DA SABEDORIA

Ana Paula Huçalo

Analine Badotti Batista

Cristina Ide Fujinaga

Fernando Stora

Francieli Aparecida Zakseski

Marina Joice Keil

Willidiane Tessari

DOI 10.22533/at.ed.3892028105

CAPÍTULO 6 68

REGULAÇÃO E DESREGULAÇÃO DO TRABALHO: TRABALHO SEXUAL, PANDEMIA, CRISE, EXCLUSÃO E ESTRATÉGIAS DE SUPERAÇÃO

Roseli Bregantin Barbosa

DOI 10.22533/at.ed.3892028106 
O LUGAR DE SUJEITO E O INDIVÍDUO: PRIMEIRAS APROXIMAÇÕES

Amanda Marques de Carvalho Gondim

José Luís Simões

Izabel Adriana Gomes de Sena Simões

DOI 10.22533/at.ed.3892028107

CAPÍTULO 8 90

JOGOS DOS POVOS INDÍGENAS: REDES DE INTERDEPENDÊNCIAS

Deoclecio Rocco Gruppi

DOI 10.22533/at.ed.3892028108

CAPÍTULO 9 108

ENTRE SOCIABILIDADES E DESIGUALDADES: AS REDES DE APOIO NAS RUAS

Anne Gabriele Lima Sousa de Carvalho

DOI 10.22533/at.ed.3892028109

CAPÍTULO 10

DINÂMICAS DE AÇÃO DOS FISIOTERAPEUTAS PORTUGUESES TENDÊNCIAS, PROBLEMAS E PERSPECTIVAS

Paula Soares

DOI 10.22533/at.ed.38920281010

CAPÍTULO 11 135

DINÂMICAS DA FAMÍLIA EMPRESÁRIA, REFLEXIVIDADE E A SUCESSÃO: A FERRAMENTA DO PROTOCOLO FAMILIAR

Ana Paula Marques

António Nogueira da Costa

Paula Freire

DOI 10.22533/at.ed.38920281011

CAPÍTULO 12

COMUNIDADE DE MOTOCICLISTAS: UMA ABORDAGEM SOBRE UM MOTO CLUBE DO PARANÁ

Karine Aparecida de Lima

Bárbara Mendes Paz Chao

Danielle Soraya da Silva Figueiredo

Fabio Antonio Matucheski Zarpelon

lara Rodrigues Vieira

Cristiana Magni

Reinaldo Knorek

DOI 10.22533/at.ed.38920281012

CAPÍTULO 13 160

AUTONOMIA PROFISSIONAL DAS NOVAS PROFISSÕES DA SAÚDE EM 
PORTUGAL - OS TÉCNICOS SUPERIORES DE RADIOLOGIA

António Fernando Caldeira Lagem Abrantes

Rui Pedro Pereira de Almeida

Luís Pedro Vieira Ribeiro

Bianca Vicente

Kevin Barros Azevedo

Carlos Alberto da Silva

Dulce Miranda

DOI 10.22533/at.ed.38920281013

CAPÍTULO 14 172

ATUAÇÃO DA DEFENSORIA PÚBLICA NO INTRAMUROS DO PRP-RS

Jiulia Estela Heling

DOI 10.22533/at.ed.38920281014

CAPÍTULO 15 180

APROXIMAÇÕES SOBRE OS CONCEITOS DE PODER E AUTORIDADE NA SOCIOLOGIA DA AÇÃO EM WEBER

Alexsandro Teixeira Ribeiro

DOI 10.22533/at.ed.38920281015

CAPÍTULO 16 193

A PROSTITUIÇÃO SOB ESCRUTÍNIO: QUANDO OS PROJETOS ANTIPROSTITUIÇÃO DO FEMINISMO ABOLICIONISTA E DE RELIGIOSOS CRISTÃOS CONVERGEM NO BRASIL

Tiago Luís Coelho Vaz Silva

DOI 10.22533/at.ed.38920281016

CAPÍTULO 17 206

A COMPLEXIFICAÇÃO DO PROCESSO CIVILIZADOR NOS DISCURSOS DA MÍDIA ESPORTIVA NO MIXED MARTIAL ARTS - MMA FEMININO

Luara Faria dos Santos

Ana Carla Dias Carvalho

DOI 10.22533/at.ed.38920281017

SOBRE O ORGANIZADOR 217

ÍNDICE REMISSIVO

218 


\section{DINÂMICAS DA FAMÍLIA EMPRESÁRIA, REFLEXIVIDADE E A SUCESSÃO: A FERRAMENTA DO PROTOCOLO FAMILIAR}

Data de aceite: 26/10/2020

\section{Ana Paula Marques}

Universidade do Minho

Braga, Portugal

ORCID: 0000-0002-9458-2915

\section{António Nogueira da Costa Instituto Politécnico da Maia \\ Maia, Portugal \\ ORCID: 0000-0002-8482-5266}

Paula Freire

Universidade do Minho

Braga, Portugal

Artigo revisto, publicado nas Atas do $X$ Congresso Português de Sociologia - Na era da "pós-verdade"? Esfera pública, cidadania e qualidade da democracia no Portugal contemporâneo, Associação Portuguesa de Sociologia (APS). Lisboa, 2018.

RESUMO: O projeto "Roadmap para as empresas familiares portuguesas” (2016-2018), financiado pelo NORTE 2020/ FEDER, liderado pela Universidade do Minho, conta com a parceria da Associação Empresarial de Portugal (AEP). Teve como objetivo central mapear as empresas familiares do Norte do país para conhecer e avaliar o seu impacto na economia local, nacional e internacional (Marques, 2018). Na concretização deste mapeamento das empresas familiares, conhecidas pela sua relativa invisibilidade (político - institucional e económico - social) organizou-se um Ciclo de 8 workshops para as empresas familiares da região Norte, distribuída pelas 8 N.U.T. III, ao longo dos meses de maio 2017 a fevereiro 2018, subordinado à temática "Empresas Familiares: Enfrentar os Desafios, Assegurar a Continuidade". Tratando-se de uma temática transversal foi-nos possível sistematizar um conjunto de preocupações e desafios comuns aos testemunhos dos/as empresário/as que participaram, em especial, no que diz respeito à questão da sucessão da empresa. Três aspetos merecem ser destacados: 1) participação das empresas familiares em dinâmicas coletivas de partilha e discussão de tópicos internos; 2) importância da "voz" das empresas familiares na sinalização de preocupações e desafios comuns, particularmente tendo em conta a emergência de uma nova geração de empresários/as mais qualificado/as e/ou atuando em mercados competitivos e globais; 3) importância da ferramenta do protocolo familiar como boa prática de governo da empresa familiar e da família empresária. Este último aspeto merecerá particular destaque já que o protocolo familiar é um processo que visa definir e regular os três principais poderes de uma empresa familiar - o poder dos sócios, o poder da gestão e o poder da família - profissionalizar a família empresária e consequentemente auxiliar na continuidade do negócio ao longo das consecutivas gerações.

PALAVRAS-CHAVE: Portugal, Família Empresária, Sucessão, Reflexividade, Poder, Protocolo Familiar.. 


\section{DYNAMICS OF THE ENTREPRENEURIAL FAMILY, REFLEXIVITY AND SUCCESSION: THE TOOL OF THE FAMILY PROTOCOL}

ABSTRACT: The "Roadmap for Portuguese Family Businesses" (2016-2018) is a project funded within the framework of NORTE-02-0853-FEDER-000018 and is headed by the University of Minho (Portugal), in co-promotion with the Portuguese Entrepreneurial Association (AEP). Its main objective consisted in analyzing and assessing the impact of the family businesses of the North of Portugal on the local, national, and international economy (Marques, 2018). In order to accomplish this mapping of family businesses, known for their relative invisibility (political-institutional and economic-social), a cycle of 8 workshops was organized for family businesses in the North region, distributed by 8 N.U.T. III throughout the months of May 2017 to February 2018, under the topic "Family Businesses: Facing the Challenges, Ensuring Continuity". Since this is a cross-cutting theme to the various workshops, a set of common concerns and challenges were systematized considering the testimonies of the businessmen who participated, especially regarding the question of the firm's succession. Three aspects should be highlighted: 1) participation of family businesses in collective dynamics of sharing and discussion of internal topics; 2) importance of the "voice" of family businesses in signaling common concerns and challenges, due to the emergence of a new and more qualified generation of entrepreneurs and/ or operating in competitive and global markets; 3 ) importance of the "family protocol" tool as a good governance practice for the family business and the business family. This last aspect will be given particular emphasis since the family protocol is a process that aims to define and regulate the three main powers of a family business - the power of the partners, the power of management and the power of the family - to professionalize the entrepreneurial family and consequently support business continuity over consecutive generations.

KEYWORDS: Portugal, Family Business, Succession, Reflexivity, Power, Family Protocol.

\section{I INTRODUÇÃO}

Com uma visão de longo prazo, as Empresas Familiares (EFs) contribuem significativamente para o PIB e o emprego, para a inovação e desenvolvimento das comunidades locais, constituindo um dos pilares essenciais do crescimento da economia de qualquer país. Na verdade, as empresas familiares constituem a forma empresarial dominante, sendo o seu sucesso e a longa estabilidade fundamentais para a economia e sociedade. Porém, um dos maiores problemas que as empresas familiares enfrentam na Europa e em Portugal é a falta de visibilidade políticoinstitucional, onde não existem ainda estatísticas oficiais precisas e atualizadas sobre este sector da economia. Existem apenas estimativas que exprimem a importância desta tipologia empresarial no cômputo geral das empresas na economia privada, variando de país para país.

O presente artigo suporta-se no projeto "Roadmap para Empresas Familiares 
Portuguesas" (NORTE-02-0853-FEDER-000018), em co-promoção com a Associação Empresarial de Portugal (A.E.P.), e financiado pelo Norte 2020 e pelo F.E.D.E.R. (Fundo Europeu de Desenvolvimento Regional). Este projeto prosseguiu um duplo objetivo estratégico: (1) mapear as empresas familiares da Região Norte, que podem ser pequenas, médias ou grandes; (2) e avaliar o seu impacto na economia local, nacional e internacional, tendo em conta a dinâmica de criação de emprego, internacionalização e inovação do investimento, por um lado, e, por outro, a profissionalização da gestão e de governo das empresas familiares. Tratase de um projeto que visou mapear esta tipologia empresarial dominante no tecido económico português, caracterizá-las e identificar principais desafios e tendências emergentes (Marques, 2018).

$\mathrm{Na}$ concretização deste mapeamento das empresas familiares, conhecidas pela sua relativa invisibilidade (político-institucional e económico-social), organizouse um Ciclo de 8 workshops para as empresas familiares da região Norte, distribuída pelas 8 N.U.T. III ao longo dos meses de maio 2017 a fevereiro 2018. A sigla N.U.T. é o acrónimo de "Nomenclatura das Unidades Territoriais para Fins Estatísticos", sistema hierárquico de divisão do território em regiões. A região corresponde ao nível II de divisão do país em cinco grandes regiões, sendo que este projeto se focou apenas na região Norte, nível II da hierarquização, e contemplou 8 unidades territoriais, que correspondem ao nível III.

Nestes 8 workshops, subordinado à temática "Empresas Familiares: Enfrentar os Desafios, Assegurar a Continuidade”, estiveram envolvidos, em média, entre 12 e 20 empresários/as familiares, desde assistência à apresentação de testemunhos em primeira pessoa. Tratando-se de uma temática transversal aos vários workshops foi-nos possível sistematizar um conjunto de preocupações e desafios comuns aos testemunhos dos/as empresários/as que participaram, em especial, no que diz respeito à questão da sucessão da empresa. Neste contexto, a ferramenta do protocolo familiar afigura-se com potencial efetivo para o planeamento da sucessão empresarial, contribuindo para as boas práticas do seu governo, a continuidade da empresa sob o controlo da família e a própria coesão familiar. A partir desta experiência, foi-nos possível: 1) dar conta dos processos de participação das empresas familiares em dinâmicas coletivas de partilha e discussão de tópicos internos; 2) destacar a importância da "voz" das empresas familiares na sinalização de preocupações e desafios comuns, particularmente tendo em conta a emergência de uma nova geração de empresário/as mais qualificado/as e/ou atuando em mercados competitivos e globais; 3) pôr em evidência a importância da ferramenta do "protocolo familiar" como boa prática de governo da empresa familiar e da família empresária. Este último aspeto merecerá particular destaque já que o protocolo familiar é um processo que visa definir e regular os três principais poderes de uma 
empresa familiar - o poder dos sócios, o poder da gestão e o poder da família profissionalizar a família empresária e consequentemente auxiliar na continuidade do negócio ao longo das consecutivas gerações.

\section{I PROJETO ROADMAP PARA EMPRESAS FAMILIARES}

\subsection{Objetivos e enfoques metodológicos}

Com uma duração de dois anos (2017-2018), o projeto "Roadmap para Empresas Familiares Portuguesas", financiado pelo NORTE2020 e FEDER prosseguiu um duplo objetivo estratégico: (1) mapear as empresas familiares da Região Norte, que podem ser pequenas, médias ou grandes; (2) e avaliar o seu impacto na economia local, nacional e internacional, tendo em conta a dinâmica de criação de emprego, internacionalização e inovação do investimento, por um lado, e, por outro, a profissionalização da gestão e de governo das empresas familiares.

Para sua operacionalização, este projeto desenvolveu-se a partir de três enfoques metodológicos, com o objetivos específicos associados a cada um deles. Em seguida, expõem-se brevemente cada um deles (cf. Figura 1).

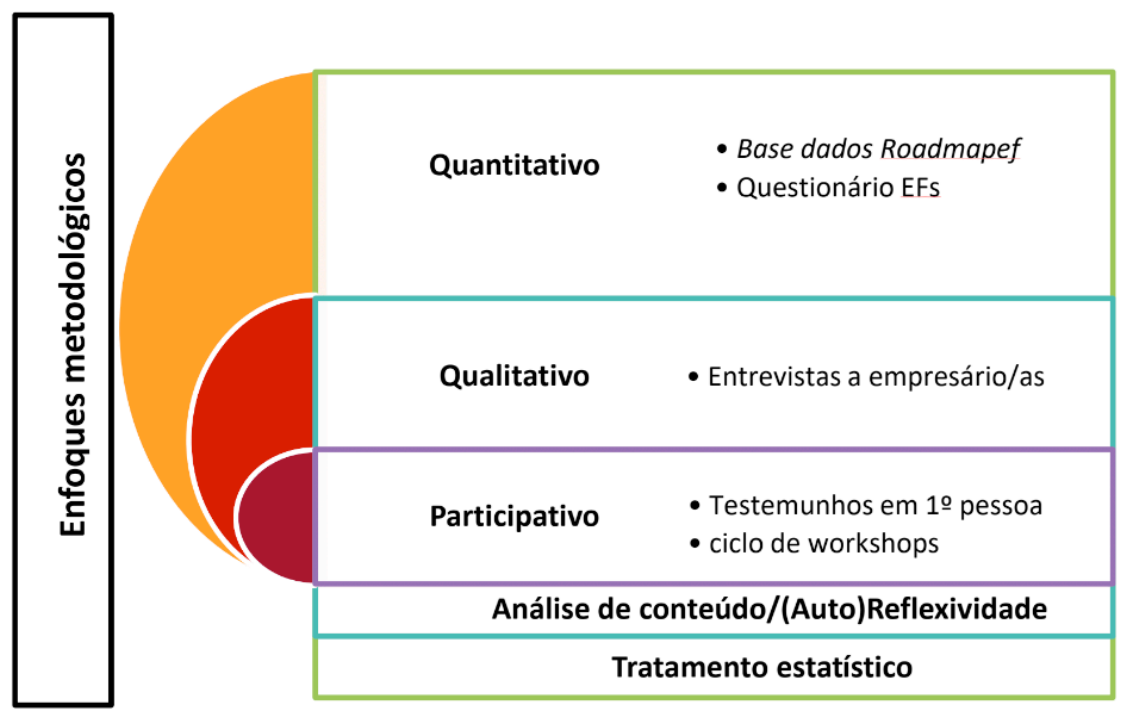

Figura 1-Desenho Metodológico

No "enfoque quantitativo", visou-se criar uma base de dados que nos permitisse saber quantas são as empresas familiares, no sentido de as mapear e elaborar a sua radiografia com base num conjunto de indicadores chave. Para isso, foi importante estabilizar o conceito de empresa familiar, tendo a nossa opção 
recaído na proposta de definição de empresas familiares avançada pelo Grupo de Peritos criado pela Comissão Europeia (COM, 2009). Note-se que a literatura especializada sobre o tema elenca mais de 90 definições e expõe a dificuldade da sua operacionalidade e consequente comparabilidade em termos não só nacionais, mas também internacionalmente. Para tal, assumem quatro elementos ou dimensões a serem contempladas na identificação das empresas familiares, distinguindo-se, assim das empresas não familiares. Esses elementos são:

1. a maior parte das decisões é tomada pelo fundador da empresa, ou por aquele que recebeu o legado da empresa enquanto herdeiro natural, ou familiar indireto;

2. a maioria da tomada de decisões pode ser indireta ou direta;

3. pelo menos um ou mais familiares estão envolvidos no controlo da empresa;

4. e, finalmente, as empresas registadas são consideradas familiares quando a pessoa que a criou ou os seus familiares e descendentes possuem $25 \%$ de ações (capital da mesma).

Com esta proposta de definição, duas ilações relevantes merecem ser destacadas. Primeira, a de que é possível considerar uma empresa familiar que ainda não passou por um processo de sucessão. Nesse sentido, não se partilha a perspetiva dos autores que apontam o critério da ocorrência de uma geração (pelo menos de uma geração) como condição para se definir a empresa familiar, constituindo per si critério exclusivo. Pelo contrário, poderemos ter empresas com idades distintas preparadas ou não para a sucessão, planeando-a através de um protocolo familiar (Costa, del Rio, 2012). A segunda ilação resulta de ser possível contemplar neste leque de empresas familiares os proprietários individuais em regime de autoemprego desde que a empresa tenha personalidade jurídica, permitindo a mesma possa ser legalmente transferida.

Até abril 2018, a Base de dados Roadmaef mapeou 41496 empresas familiares da região Norte, cumprindo o principal objetivo de saber quantas são as empresas familiares e onde as mesmas se encontram localizadas na região Norte. $\mathrm{Na}$ fase subsequente, foi elaborado e aplicado um questionário (online através da plataforma LimeSurvey e presencial, entre junho a julho 2017) às empresas familiares que integram a nossa base de dados, ao permitindo sinalizar diferentes perfis desta tipologia empresarial. O plano de amostragem orientou-se pela representatividade da distribuição das empresas familiares por N.U.T. III e por dimensão da empresa definida por número de trabalhadores (cf. Tabela 1). 


\begin{tabular}{|c|c|c|c|c|c|}
\hline \multirow[b]{2}{*}{ NUT III } & \multicolumn{4}{|c|}{$\mathrm{N}^{\circ}$ de trabalhadores } & \multirow[b]{2}{*}{ Total } \\
\hline & $\begin{array}{r}\text { Micro } \\
\leq 3\end{array}$ & $\begin{array}{r}\text { Micro } \\
(4-9)\end{array}$ & $\begin{array}{l}\text { Pequena } \\
(10-49)\end{array}$ & $\begin{array}{r}\text { Média e } \\
\text { Grande } \\
\text { Empresa } \\
(\geq 50)\end{array}$ & \\
\hline Alto Minho & $\begin{array}{r}10 \\
14.9\end{array}$ & $\begin{array}{r}28 \\
41.8\end{array}$ & $\begin{array}{r}20 \\
29.9\end{array}$ & $\begin{array}{r}9 \\
3.4\end{array}$ & $\begin{array}{r}67 \\
5.8\end{array}$ \\
\hline Alto Tâmega & $\begin{array}{r}2 \\
9.5\end{array}$ & $\begin{array}{r}10 \\
47.6\end{array}$ & $\begin{array}{r}6 \\
28.6\end{array}$ & $\begin{array}{r}3 \\
14.3\end{array}$ & $\begin{array}{r}21 \\
1.8\end{array}$ \\
\hline Área Metropolitana do Porto & $\begin{array}{r}200 \\
36.8\end{array}$ & $\begin{array}{r}146 \\
26.9\end{array}$ & $\begin{array}{r}142 \\
26.2\end{array}$ & $\begin{array}{r}55 \\
10.1\end{array}$ & $\begin{array}{r}543 \\
47.3\end{array}$ \\
\hline Ave & $\begin{array}{r}25 \\
18.1\end{array}$ & $\begin{array}{r}40 \\
29.0\end{array}$ & $\begin{array}{r}45 \\
32.6\end{array}$ & $\begin{array}{r}28 \\
20.3\end{array}$ & $\begin{array}{r}138 \\
12.0\end{array}$ \\
\hline Cávado & $\begin{array}{r}45 \\
23.8\end{array}$ & $\begin{array}{r}56 \\
29.6\end{array}$ & $\begin{array}{r}59 \\
31.2\end{array}$ & $\begin{array}{r}29 \\
15.3\end{array}$ & $\begin{array}{r}189 \\
16.5\end{array}$ \\
\hline Douro & $\begin{array}{r}16 \\
30.2\end{array}$ & $\begin{array}{r}18 \\
34.0\end{array}$ & $\begin{array}{r}13 \\
24.5\end{array}$ & $\begin{array}{r}6 \\
11.3\end{array}$ & $\begin{array}{r}53 \\
4.6\end{array}$ \\
\hline Tâmega e Sousa & $\begin{array}{r}25 \\
22.7\end{array}$ & $\begin{array}{r}28 \\
25.5\end{array}$ & $\begin{array}{r}34 \\
30.9\end{array}$ & $\begin{array}{r}23 \\
20.9\end{array}$ & $\begin{array}{r}110 \\
9.6\end{array}$ \\
\hline Terras de Trás-os-Montes & $\begin{array}{r}3 \\
11.1\end{array}$ & $\begin{array}{r}14 \\
51.9\end{array}$ & $\begin{array}{r}8 \\
29.6\end{array}$ & $\begin{array}{r}2 \\
7.4\end{array}$ & $\begin{array}{r}27 \\
2.4\end{array}$ \\
\hline Total & $\begin{array}{r}326 \\
28.4\end{array}$ & $\begin{array}{r}340 \\
29.6\end{array}$ & $\begin{array}{r}327 \\
28.5\end{array}$ & $\begin{array}{r}155 \\
13.5\end{array}$ & 1148 \\
\hline
\end{tabular}

Tabela 1 - Distribuição da amostra final por N.U.T. III e dimensão Fonte: Questionário EFs

A informação recolhida sobre empresas familiares na região Norte, por via do questionário, orientou-se para as dimensões e indicadores mais relevantes, designadamente: i) identificação das empresas; ii) caracterização genérica da atividade empresarial; iii) estrutura e governação familiar; iv) Profissionalização das famílias empresárias; v) caracterização sociobiográfica do respondente do questionário que poderá ser o próprio fundador ou gestor com conhecimento geral da empresa familiar.

Em articulação com esta fase do projeto, privilegiou-se uma metodologia qualitativa, tendo-se realizado 23 entrevistas aprofundadas a empresário/as familiares nos contextos das respetivas organizações. Para além de esta atividade se justificar como suporte à conceção do questionário, com a sinalização das questões a formular, permitiu reconstruir a "história" e "cultura" da empresa familiar e redes de parentesco, recuperar a trajetória do/a fundador/a, principais momentos críticos de viragem/ readaptação/ transformação do negócio, bem como questões relacionadas com situação presente e desafios para o futuro próximo (Marques, 2018).

Na dinamização das ações previstas no projeto, foi imprescindível incentivar 
a participação direta e indiretamente das empresas familiares. Neste enfoque participativo, destaca-se a organização do ciclo de worskhops direcionado para empresas familiares, com lugar em cada uma das N.U.T. III região Norte, para além da participação de empresários/as e especialistas nos seminários internacionais que tiveram lugar no decorrer do projeto. Este ciclo decorreu entre maio 2017 a fevereiro 2018 e foi realizado em cada uma das N.U.T. III da região Norte e subordinado à temática transversal "Empresas Familiares: Enfrentar os Desafios Assegurar a Continuidade".

Nos oito workshops distribuídos pela Área Metropolitana do Porto, Alto Minho, Cávado, Ave, Tâmega e Sousa, Douro e Terras de Trás-os-Montes, foram convidados empresários tendo em conta a região e o predomínio do setor de atividade. Em cada um dos workshops estiveram envolvidos, em média, entre 12 a 20 empresários/as familiares. Foi-nos possível sistematizar a partir dos testemunhos dos/as empresários/as que participaram, em especial, no que diz respeito à questão da sucessão da empresa, da profissionalização do negócio, da feminização dos líderes, dos conflitos família e negócio, da continuidade da empresa sob o controlo da família e coesão familiar.

$\mathrm{Na}$ discussão desta temática transversal aos vários workshops, destaca-se a importância da "voz" das empresas familiares na sinalização de preocupações e desafios comuns, particularmente tendo em conta a emergência de uma nova geração de empresário/as mais qualificado/as e/ou atuando em mercados competitivos e globais. Outros temas abordados foram, por exemplo, a questão da sucessão da empresa, da profissionalização do negócio, da feminização dos líderes, dos conflitos família e negócio, da continuidade da empresa sob o controlo da família e coesão familiar. Quanto à questão "sensível" da sucessão, a ferramenta do "protocolo familiar" afigura-se com potencial efetivo para o planeamento da passagem de "testemunho" para a geração seguinte, contribuindo para as boas práticas do seu governo, a continuidade da empresa sob o controlo da família e a própria coesão familiar.

\subsection{Dinâmica coletiva dos workshops}

Na organização dos workshops, presidiu uma preocupação comum: convidar empresários de ambos os sexos, localizados nas diversas N.U.T. III da região Norte, sob um tema comum: assegurar a continuidade das empresas familiares no contexto da globalização da economia. Para isso, foram contactadas entidades como Câmaras Municipais e Associações Empresarias de cada N.U.T.Ill da região Norte que, mediante as suas agendas e disponibilidades, mas também mediante os horários preferências dos empresários locais nos acolheram nas suas instalações ou nos encaminharam par um contacto que melhor se enquadrasse na atividade que 
estávamos a propor.

Após estes contactos (via e-mail ou telefone) as Câmaras e/ou Associações que se disponibilizaram a ser nossas parceiras foram:

- $\quad$ Crédito Agrícola de Vila Verde e Terras do Bouro;

- $\quad$ Confraria dos Vinhos do Douro;

- Caixa do Crédito Agrícola - Caixa do Noroeste;

- $\quad$ NERBA - Associação Empresarial do Distrito de Bragança;

- Casa do Território;

- Associação Empresarial de Amarante;

- $\quad$ Oliva Creative Factory e SANJOTEC;

- Associação Empresarial Botiquense.

O ciclo de workshops decorreu de 26 de maio de 2017 a 3 de julho de 2018. Apesar de 7 dos workshops terem sido realizados em 2017, o último referente à N.U.T. do Alto Tâmega apenas se realizou no ano de 2018 devido a condicionantes alheias à nossa organização.

O contacto entre a equipa do projeto "Roadmap para Empresas Familiares" e as associações de acolhimento foi um ponto-chave na organização deste ciclo de workshops tanto no que diz respeito à marcação e uma data e hora que fosse favorável às entidades, como na divulgação e captação de participantes para o mesmo.

Neste ciclo de 8 workshops distribuídos pela região Norte estiveram presentes 107 participantes no total, sendo 37 do sexo feminino e 70 do sexo masculino. A entidade recetora do workshop assumiu um papel primordial na divulgação do evento uma vez que para além de já possuir uma base de dados com empresários locais, esta conhece as suas particularidades e interesses de modo a contactar os futuros participantes que poderiam vir a ter interesse no evento. Neste processo de divulgação e captação, a Universidade do Minho disponibilizou todos os meios para permitir o bom funcionamento do evento. Desde a conceção, impressão e envio dos cartazes, criação e envio de e-mails e notícias tipo no sentido de uniformizar e melhor esclarecer os futuros participantes até à disponibilização de material de apoio ao workshop como capas, blocos, canetas, entre outros. No sentido de melhor registar e organizar o número de participantes foram criados 8 surveys de inscrição por parte da Universidade do Minho. Este survey encontrava-se presente na divulgação das duas entidades e possibilitava aos participantes fazer a sua inscrição online. A modalidade de inscrições também era possível através de e-mail para uma das 
duas entidades parceiras que, entrava em contacto com a outra no sentido de dar conhecimento do número de inscrições recebidas. Foi necessário um contacto diário entre as duas entidades até ao dia do evento no sentido de o melhor organizar e prever quaisquer questões que eventualmente pudessem surgir

Demonstrados os processos referentes ao "pré-workshop", no que diz respeito ao dia do evento o processo foi bastante simples na generalizada dos casos uma vez que todos os aspetos já se encontravam acertados anteriormente, como é o caso do material necessário e organização da sala. A equipa, após chegar ao local, montava o local para acreditação dos participantes, distribui as capas com informações relevantes do projeto e testava os meios informáticos no sentido de estes não apresentarem anormalidades de funcionamento.

Na dinâmica coletiva proporcionada pelos workshops, foi possível a partilha e a discussão de tópicos internos da família empresária, com destaque nos testemunhos em "primeira pessoa" na sinalização das preocupações, desafios e boas práticas.

Os empresários, no geral, destacavam problemas relacionados com questões da sucessão da empresa, da profissionalização do negócio, da feminização dos líderes, dos conflitos família-negócio e da continuidade da empresa sob o controlo da família. Foram vários os empresários que apresentaram a questão da sucessão da empresa como um dos seus maiores desafios. Em vários casos, a geração mais recente de empresários destacou o facto da geração anterior não abdicar do controlo total da empresa, tentando por vezes reverter algumas decisões da administração atual.

O caso da feminização dos líderes foi um dos aspetos bastante abordado nas sessões, principalmente no caso do workshop realizado na Associação Empresarial do Distrito de Bragança. Contrariamente aos discursos observados nos outros workshops, as participantes deste workshop não referiram a sua entrada como líderes como um problema ou como sendo difícil. O mesmo se sucedeu no caso de São João da Madeira, onde o número de mulheres empresárias se apresentou superior ao número de homens empresários (8 mulheres e 5 homens).

Decorrida a sessão, o debate geralmente alargava-se no exterior do auditório acompanhado por um café. Este momento "pós-workshop" apresentou-se bastante importante no que diz respeito aos contactos para as entrevistas posteriores. Foi na "pausa para o café" que foi possível alcançar um contacto de maior intimidade onde todos os empresários se mostravam disponíveis para falar dos seus casos pessoais, problemas e até situações de algum humor no que diz respeito aos seus negócios.

No dia seguinte ao workshop, a equipa do projeto "Roadmap para Empresas Familiares Portuguesas", para além do envio de um e-mail de agradecimento à entidade parceira, procedeu do mesmo modo com os participantes. As fotos 
registadas pela equipa Roadmap encontram-se no site do projeto acompanhadas de uma notícia referente ao evento. Estas fotos foram também enviadas para a entidade parceira.

Com o intuito de melhor perceber a relevância do workshop e do projeto "Roadmap para Empresas Familiares Portuguesas" para as famílias empresárias e se este teria sido útil para estas no que diz respeito aos temas abordados, criamos um "mini-questionário" que era fornecido aos empresários no momento da acreditação. Este questionário possuía apenas quatro perguntas:

- As informação divulgadas na sessão de esclarecimento do projeto foram úteis para sim e/ou para o seu negócio?

- Este workshop foi útil para si e/ou para a sua empresa?

- Que outros temas/assuntos no âmbito das empresas familiares gostaria que fossem abordados em eventos futuros?

- Deseja fazer algum comentário ou sugestão adicional?

No que diz respeito tanto à utilidade das informações referentes ao projeto, como na utilidade da sessão em si, 100\% dos participantes responderam que "Sim", que as informações apresentadas foram uteis para os empresários ou para as empresas que representam.

Relativamente aos temas e assuntos de maior relevância que os participantes gostariam de ver abordados em eventos futuros anunciados no questionário, a "Gestão de conflitos" (66.6\%) foi o tema que estes anunciaram com maior frequência; seguindo-se a "Inovação" (47.60\%) e a "Sucessão de Liderança" (42.85\%).

\section{I EMPRESA FAMILIAR E SUCESSÃO: A FERRAMENTA DO PROTOCOLO FAMILIAR}

Esta tipologia empresarial assume singularidades que se expressam, em grande medida, pela influência das estruturas familiares na atividade económica em si. Uma dessas influências expressa-se de forma muito patente na questão da sucessão da liderança e/ ou propriedade. Com efeito, uma família que controle uma empresa familiar tem como intrínseca a vontade de assegurar a sua transmissão e continuidade pelas sucessivas gerações. No entanto, os dados refletem que esta vontade não é de fácil concretização.

Um dos primeiros e mais citados estudos sobre empresas familiares, realizado em Illinois por Jonh $\mathrm{L}$. Ward, salienta que em sessenta anos de vida $80 \%$ das empresas desapareceram e, das restantes, somente $13 \%$ se mantiveram sob o controlo das respetivas famílias fundadoras. Este período de tempo reflete o envolvimento de duas ou três gerações familiares, o que leva ao suporte dos 
empíricos ditos populares, comuns na maioria dos países que permitem a existência de empresas familiares: Pai Rico, Filho Nobre, Neto Pobre.

Em 1978, Renato Tagiuri e John Davis desenvolveram um modelo que representa a empresa familiar como um sistema que agregador de três círculos que refletem a existência e relacionamento de outros tantos stakeholders:

- a propriedade - detentores do capital social,

- a empresa - pessoa jurídica que desenvolve o negócio,

- a família - pessoas ligadas por laços familiares que controlam a propriedade e a gestão da empresa.

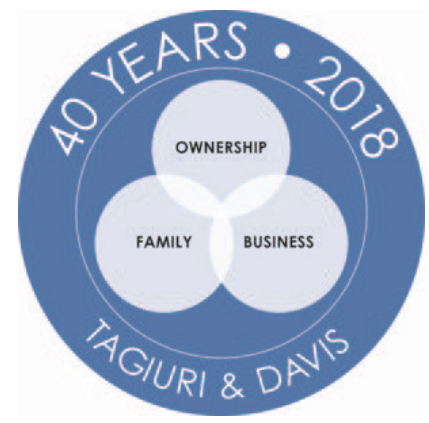

Figura 2 - Modelo dos Três Círculos

A existência da sociedade, enquanto entidade que desenvolve o negócio, e dos sócios que a controlam (proprietários do seu capital) está devidamente regulada - em especial pelo Código das Sociedades Comerciais - no entanto, a existência da família enquanto stakeholder com eles relacionados não tem suporte devidamente regulado.

Para num futuro próximo se poder chegar ao reconhecimento da família empresária como uma das partes interessadas na empresa familiar, têm sido desenvolvidos esforços no sentido de a estruturar e a profissionalizar; isto é, de lhe atribuir uma existência e capacidade de atuação conjunta para se relacionar de uma forma adequada com a empresa a que se encontra associada.

\subsection{Estruturação da Família Empresária e paralelismo com a Empresa Familiar}

No sentido de auxiliar a família empresária a alcançar os seus objetivos fundamentais: coesão em torno da empresa familiar e continuidade do património como um legado para as gerações seguintes, a mesma deve organizar-se, seguindo uma filosofia muito idêntica ao de uma sociedade comercial, com a qual 
se estabelece um paralelismo que permite visualizar a sua estruturação, a sua completa independência e a ponte para contactos com a Empresa Familiar.

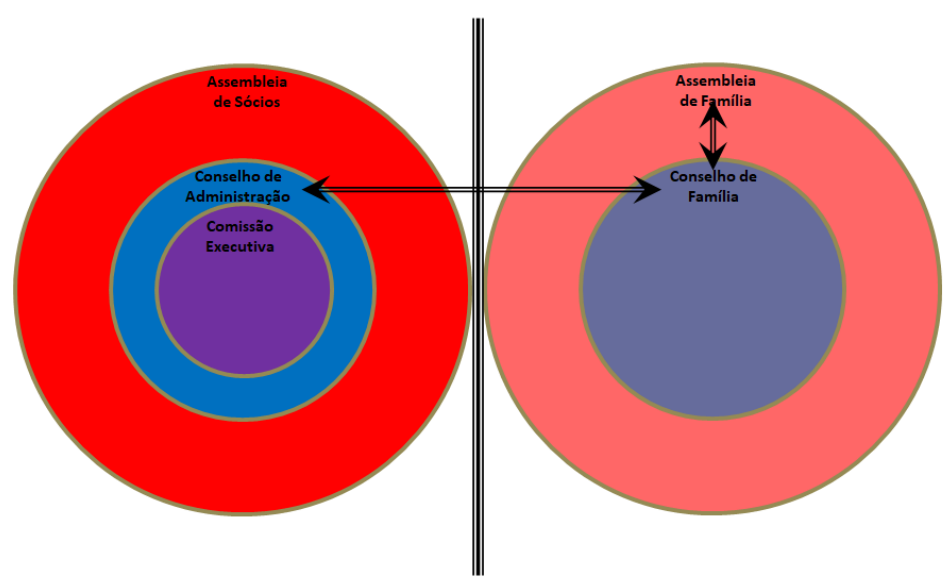

Figura 3 - Estruturação da Família Empresária e ligação à Empresa Familiar

\subsection{O Protocolo Familiar ou Constituição Familiar}

Ao não estar regulada do ponto de vista jurídico-legal, a área de conhecimento da gestão foi a primeira a identificar e a reconhecer a necessidade de considerar a família como um elemento diferenciador e impactante na empresa e, consequentemente, de protocolar a sua atuação e forma de inter-relação com a empresa que controla.

Na última década do séc. XX surge o Protocolo Familiar ou Constituição da Família como um acordo, reduzido a escrito, pelos familiares sócios de uma empresa, com o objetivo de regular a sua organização e as relações económicas e profissionais entre a família, a propriedade e a empresa (Gallo, 1992). O documento obtido é a parte mais tangível do processo que o concebe e reconhece a estruturação e regulação duma família empresária (Costa, 2017).

\subsection{Como se desenvolve e quanto tempo demora o Processo}

O protocolo familiar é normalmente desenvolvido por uma entidade externa que apoia e dinamiza todo o processo e segue uma determinada metodologia.

De forma sintética o processo de desenvolvimento utilizado pela efconsulting ${ }^{\odot}$ (Costa, 2012) considera quatro fases sequenciais: 


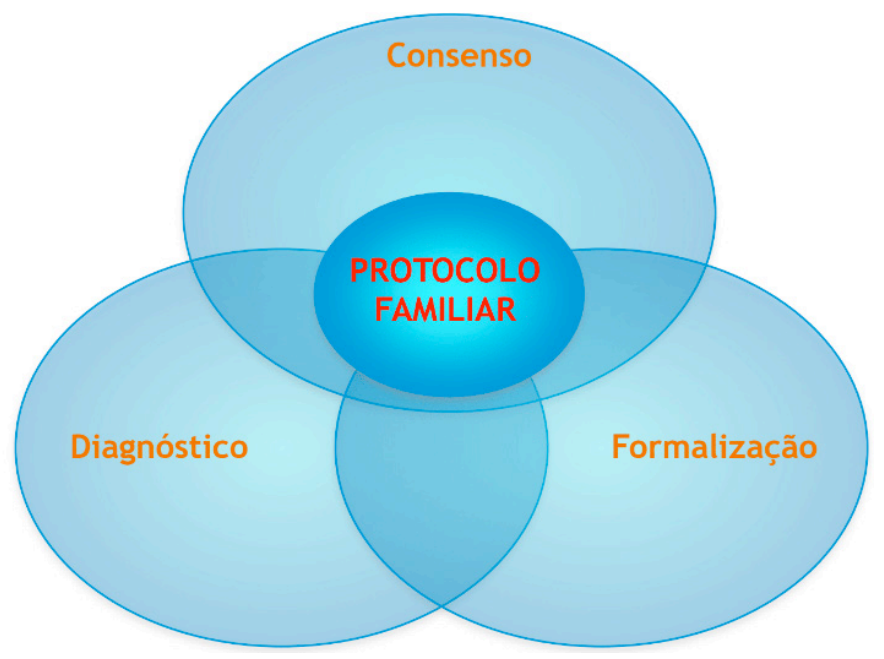

Figura 4 - As fases de desenvolvimento de um Protocolo Familiar

1. Fase de Sensibilização: explicação aos participantes de conceitos essenciais, do processo, dos principais objetivos, dos contributos esperados e esclarecimentos de dúvidas. Normalmente é uma reunião conjunta que pode ser integrada no início da fase de Diagnóstico.

2. Fase de Diagnóstico: interação da entidade externa com os participantes com o objetivo de conhecer suas posições básicas relativamente aos pontos fundamentais do protocolo. Suporta-se essencialmente em diversas reuniões individuais e questionários confidenciais e culmina com uma reunião conjunta de apresentação do diagnóstico essencial. Fase decorre num período entre 1 a 3 meses.

3. Fase de Consensos: construção de um acordo consensual global, sobre todos os pontos considerados relevantes e que devem fazer parte do documento final do protocolo. Suporta-se em reuniões individuais e de grupo (geracionais, ramos familiares ou outros) para, num processo iterativo, se desenvolver e encontrar soluções conciliadoras e abrangentes. Fase mais demorada e muito dependente da maior ou menor facilidade de se encontrar os consensos. Decorre num período entre 3 a 6 meses, podendo em determinados casos ser ultrapassar de forma significativa.

4. Fase de Formalização: agrupamento e redação num documento único Protocolo Familiar - de todos os acordos estabelecidos. Tal como a fase de consenso, é um processo iterativo de troca de documentos e reuniões de esclarecimento até à redação da sua versão definitiva. A etapa terminada com a entrega e assinatura do Protocolo Familiar, por parte de todos os participantes. Dependendo da menor ou maior necessidade de revisões, normalmente necessita de 3 a 6 meses. 


\subsection{A vinculatividade do Protocolo Familiar}

O Protocolo Familiar é um acordo entre as partes signatárias, no entanto, decorrente do seu próprio processo de desenvolvimento, fica acordado qual o nível de vinculatividade desejado. Para este fim atende-se a distintos meios:

- Internos à empresa: baseados em regulamentos da administração, regulamentos processuais ou de atuação das pessoas que assumem determinadas funções ou da estrutura organizativa da empresa;

- Jurídicos: suportados nos estatutos, em acordos parassociais, em testamentos ou doações.

\subsection{Os Órgãos da Família Empresária}

O Protocolo Familiar normalmente estrutura a família empresária suportada em dois órgãos:

- A Assembleia de Família: fórum que integra os familiares de maioridade e tem por fim assegurar a coesão da família. Recorre à informação e formação dos seus membros, delibera sobre os assuntos que lhe foram assignados e supervisiona a atuação do Conselho de Família. Reúne uma ou duas vezes por ano.

- O Conselho de Família: órgão colegial, compostos por dois a cinco membros, que tem por grandes objetivos ser o elo de ligação empresa-família e o dinamizador das ações ligadas à família empresária. Operacionaliza todas as tarefas que Ihe foram atribuídas e assume a representação da família junto de cada um dos seus membros e da empresa. Reúne duas ou seis vezes por ano.

\subsection{Empresas que possuem o protocolo familiar e sua utilidade}

Existe uma relação entre a dimensão das empresas e a existência de protocolo familiar, como o suporta o estudo desenvolvido pela Cátedra da Empresa Familiar do IESE. Das respostas obtidas ao inquérito lançado a 1.000 empresas sediadas em países de língua castelhana, verificou-se a seguinte existência de protocolo familiar nas empresas:

- com menos de 50 trabalhadores $-35,7 \%$

- entre 50 e 250 trabalhadores - $43,2 \%$

- com mais de 250 trabalhadores - $66,1 \%$.

Quando a variável de análise da empresa é o valor de faturação, constatou-se que daquelas que faturam acima de 10 milhões de euros $62,1 \%$ possuem protocolo familiar. 
Dada a significativa expressividade destes números e os custos de desenvolvimento - financeiros e de alocação de tempo das pessoas a trabalhar na empresa e da própria família - é relevante perceber a utilidade de desenvolver e possuir um protocolo familiar. Este mesmo estudo questionou se o protocolo que as empresas possuíam já tinha sido utilizado pelo menos uma vez para gerir situações específicas ligadas à relação família-empresa: $60 \%$ dos participantes responderam afirmativamente.

\section{I NOTAS FINAIS}

Genericamente definidas pela intrínseca envolvência de membros da família nos quadros de gestão e direção, as empresas de tipo familiar apresentam interessantes singularidades que as distinguem das restantes empresas, acentuando a sua importância nas economias de mercado à escala mundial. Reconhecendo-se o maior grau de resiliência e longevidade quando comparadas com as restantes empresas, as empresas familiares caraterizam-se pela preservação de valores e tradições pelas gerações futuras procurando-se desta forma estabelecer um vínculo entre a empresa e a família e, assim, garantir a manutenção do controlo da família no negócio.

Na dinâmica coletiva proporcionada pelos workshops, foi possível a partilha e a discussão de tópicos internos da família empresária, com destaque nos testemunhos em "primeira pessoa" na sinalização das preocupações, desafios e boas práticas comuns. Além disso, foi possível constitui-se num espaço formativo, potenciando a experiência de (auto) reflexividade dos próprios intervenientes no processo. Neste contexto, ficou evidente que desenvolver e implementar um protocolo familiar é uma decisão de investimento no futuro da continuidade da empresa e da família empresária e uma via de facilitar as dinâmicas associadas à passagem do legado ao longo das suas consecutivas gerações.

Prosseguir com este esforço de mapeamento desta tipologia empresarial dominante no tecido económico português, identificando suas principais e perfis e desafios emergentes é essencial como suporte ao desenvolvimento futuro de políticas públicas direcionadas ao apoio às empresas familiares.

\section{REFERÊNCIAS}

Aronoff, C. E., Ward, J. L. (2002). Family Meetings. How to build a Stronger Family and a Stronger Business. New York: Palgrave Macmillan.

Costa, A. N. (2012). O Protocolo familiar como arma anticonflito. Revista Exame, $\mathrm{n}^{\circ} 344,54-$ 59. 
Costa, A. N. (2017). Manual de Boas Práticas da Empresa familiar. DOI: 10.6084/ m9.figshare.5545141

Costa, A. N. (2018). A profissionalização da família empresária e a continuidade das empresas familiares, Centro Interdisciplinar de Ciências Sociais, https://doi. org/10.21814/1822.56256, ISBN: 978.989.99768.2.5

Costa, A. N., Negreira, F, Negreira, J. (2011). 50 perguntas essenciais sobre empresas familiares. Porto: Vida Económica.

Gallo, M. A. (1998). La sucesión en la empresa familiar. Barcelona: Colección de estudios y informes La Caixa.

Gallo, M. A., Ward, J. L. (1992). Protocolo Familiar. Nota técnica DGN-448. Navarra, IESE.

Gersick, K. F.; Davis, J. A., Hampton, M. M., Lansberg, I. (1996). Generation to Generation: Lyfe Cycles of the Family Business. Harvard: Harvard Business School Press.

Montemerlo, D., Ward, J. L. (2011). The Family Constitution. Agreements to secure and perpetuate your family and your business. New York: Palgrave Macmillan.

Marques, A. P. (2018). Empresas Familiares da Região Norte. Mapeamento, Retratos e Testemunhos. Braga: Diário do Minho.

Negreira, F., Negreira, J., Costa, A. N. (2007). Eu não vendi. Não o façam vocês. Empresa familiar e sucessão, Porto: Vida Económica.

Tàpies, J., Ceja, L. (2011). Los protocolos familiares en países de habla hispana: Cómo son y para qué se utilizan. CDI-931, IESE, Cátedra de Empresa Familiar

Ward, J. (1987). Keeping the Family Business Healthy. San Francisco: Jossey-Bass Inc., Publishers 